\title{
Accurate indoor positioning system based on modify nearest point technique
}

\author{
Omar Ibrahim Mustafa', Hawraa Lateef Joey², Noor Abd AISalam ${ }^{3}$, Ibrahim Zeghaiton Chaloob \\ ${ }^{1}$ Department of Computer Techniques Engineering, Electrical Engineering Technical College, Middle Technical University, \\ Baghdad, Iraq \\ ${ }^{2}$ Department of Computer Techniques Engineering, College of Engineering, Al-Esraa University College, Baghdad, Iraq \\ ${ }^{3}$ Department of Computer Techniques Engineering, College of Engineering, Al-Hadba'a University College, Mosul, Iraq \\ ${ }^{4}$ Department of General Management, College of Applied Science, University of Fallujah, Anbar, Iraq
}

\begin{tabular}{l} 
Article Info \\
\hline Article history: \\
Received Feb 26, 2021 \\
Revised Sep 10, 2021 \\
Accepted Oct 4, 2021 \\
\hline
\end{tabular}

\section{Keywords:}

Modify nearest point

Positioning system

RSS

$\mathrm{Wi}-\mathrm{Fi}$

Wireless InSite

\begin{abstract}
Wireless fidelity (Wi-Fi) is common technology for indoor environments that use to estimate required distances, to be used for indoor localization. Due to multiple source of noise and interference with other signal, the receive signal strength (RSS) measurements unstable. The impression about targets environments should be available to estimate accurate targets location. The Wi-Fi fingerprint technique is widely implemented to build database matching with real data, but the challenges are the way of collect accurate data to be the reference and the impact of different environments on signals measurements. In this paper, optimum system proposed based on modify nearest point (MNP). To implement the proposal, 78 points measured to be the reference points recorded in each environment around the targets. Also, the case study building is separated to 7 areas, where the segmentation of environments leads to ability of dynamic parameters assignments. Moreover, database based on optimum data collected at each time using 63 samples in each point and the average will be final measurements. Then, the nearest point into specific environment has been determined by compared with at least four points. The results show that the errors of indoor localization were less than $(0.102 \mathrm{~m})$.
\end{abstract}

This is an open access article under the CC BY-SA license.

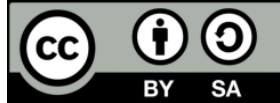

\section{Corresponding Author:}

Omar Ibrahim Mustafa

Department of Computer Techniques Engineering, Electrical Engineering Technical College, Middle

Technical University

Baghdad, Iraq

Email: omdell_70@yahoo.com

\section{INTRODUCTION}

In the last decade, positioning systems have seen demand that encouraged researchers and developers to construct positioning systems based on new techniques and methods. The aims of those techniques and methods are increase the reliability of systems in order to correspond with positioning system environments. Where, indoor localization could be used in sensitive issue such as, find victims, loss children, and guide firefighters. There are number of methods to design indoor positioning such as, time of arrival (TOA) [1], time deference of arrival (TDOA) [2], angel of arrival (AOA) [3], receive signal strength (RSS) [4]. The global positioning system (GPS) is common system which widely used as a prefer system, however, such system is suffer into big building lead to deny service [5].

In other hand, there are many challenges in indoor systems such as, multi path phenomenon, multi user interference, and regressive [6], [7]. Therefore, many systems designed to mitigate those problems and carried out positioning systems with high accuracy. The authors in [8] was applied positioning system using 
scattering model. In this study, the authors have been tried to distinguish between deference environments to develop system deal with each scenario. Many techniques investigated through apply sectoring model such as statistics measurements which matching for each moment, also expectation maximization in addition to Bayesian algorithms was applied. The results that obtain from proposed algorithms are more accurate in estimate position compare with traditional algorithms. The authors in [9] have been proposed (RITEM) algorithm to improve indoor localization based on TOA. The authors implemented their algorithm by classify the ranging error based on signal measurements in data transmission. This classification includes four classes, with RSS and error interval for each class according to measurements which proceeded initialization of positioning system. In this case, the proposed algorithm has ability to estimate ranging error in online. The authors in [10] evaluated new algorithm to address the non-line-of-sight (NLOS) impact subsequently, improve system accuracy.

To utilize indoor positioning system based on both TOA and RSS, they applied the Triangle Centroid algorithm (TC) based on couple area. The idea of selected two areas is obtain the accurate measurements from each geometric area which selected. By substitute the enhance data into TC algorithm, the localization system will be implemented. Even with those solution, there are many challenges lead to rang of errors such as the unstable RSS measurements and the system could be suitable for some environments will suffer in other. Hence, the systems should take in account all challenges to carry out optimum system work under any scenario. Such system construct with accurate signal measurements and high quality in implementations and calculations by assigned suitable parameters. To reach that, modify nearest point (MNP) proposed in this paper. Such proposal aims to build accurate database to be reference measurements based on real measurements using number of samples. The nearest point will apply to find accurate RSS measurements lead to estimate correct position based on suitable parameters.

\section{LOCALIZATION BASED ON RSS AND TOA}

As mentioned Wi-Fi is common way to estimate location using RSS, the problem with this method is unstable RSS due to harsh indoor environments specifically in NLOS scenario and crowded signals. With those challenges, RSS measurements will be unpredictable. To solve those problems, Wi-Fi fingerprint technique can be used to find accurate RSS and then accurate distance based on those signal as the authors in [11]-[20], [21], [22]. The weighted K-nearest neighbor (WKNN) algorithm was used in estimate RSS by using nearest fingerprint to estimate location. Two scenarios presented in traditional WKNN, online scenario in addition to offline one. In offline situation there is database which contain measurements of signals measured as a reference. In online phase, actual RSS was measured and compared with reference RSS which measure previously to estimate the accurate RSS as in (1) [11].

$$
d_{e s_{i}}=\left(\sum_{i=1}^{m}\left|m_{R S S}-r e f_{R S S}\right|^{2}\right)^{\frac{1}{2}}
$$

Where $\mathrm{m}_{\mathrm{RSS}}$, is RSS which found in online phase, ref $_{\mathrm{RSS}}$, is reference RSS which measured in offline phase and $\mathrm{m}$ is the number of access points (APs). Each reference points have been saved its euclidean distance in data base, with K-Nearest Neighbors (KNN), the postion with coordinate of ( $\mathrm{x}, \mathrm{y}$ ) has minimum $\mathrm{K}$ reference points will be found as in (2):

$$
(x . y)=\frac{1}{K} \sum_{i=1}^{K}\left(x_{i} \cdot y_{i}\right)
$$

The WKNN used to find the average of weight, hence, find suitable location as in (3):

$$
(x, y)=\frac{\sum_{i=1}^{K} \frac{\left(x_{i} \cdot y_{i}\right)}{d i s_{i}}}{\sum_{i=1}^{K} \frac{1}{d i s_{i}}}
$$

To mitigate regressive signal problem, the value of RSS at each scenario will be stored in fingerprint data base. To implement that reference points defined as, $R P_{i}=\left[R P_{i . O P 1} \cdot R P_{i . o p 2} \ldots \ldots \ldots R P_{i . o p n}\right]$ where $i$ is number of $\mathrm{RP}$, and $\mathrm{RP}_{\mathrm{i.opj}}=\left[\mathrm{rss}_{\mathrm{i.OPj} .1} \cdot \mathrm{rss}_{\mathrm{i.OPj} .2} \ldots \ldots \ldots \mathrm{rss}_{\mathrm{i.OPj} . \mathrm{t}}\right]$, where $\mathrm{j}$ is number of APs. In this case the RPs have been matched with each $\mathrm{APs}$, in fact, $\mathrm{rss}_{\mathrm{i} . \mathrm{j}}$ is equal to test points in actual estimate position. Where $\mathrm{TPs}=\left[\mathrm{TP}_{\mathrm{OP} 1} \cdot \mathrm{TP}_{\mathrm{OP} 2} \ldots . \mathrm{TP}_{\mathrm{OPN}}\right]$, the smallest distance between $\mathrm{TP}_{\mathrm{OPj}}$ and $\mathrm{RP}_{\mathrm{i} . \text { opj }}$ calculated as in (4):

$$
d_{\text {smallest }}=\min \left|r s s_{j}-r s s_{i . o p j . . k}\right|
$$


where $\mathrm{k}$ is the result of $(\mathrm{k}$ th) fingerprint which stored in data base.

Now the smallest distance has been presented after compared with each APs, the final distance will be determine as in (5) [11]:

$$
\operatorname{dis}_{i}=\left(\sum_{i=1}^{m} d_{\text {smallest }}^{2}\right)^{\frac{1}{2}}
$$

Also, there is ability to apply multi matched with nearest APs as in (6) [11]:

$$
d i s_{i}=\left(\sum_{i}^{m}\left(\frac{d_{\text {smallest }^{2}+\left|r s s_{j}-\overline{r s s}_{i . o p j}\right|^{2}}}{r s s_{j}}\right)\right)^{\frac{1}{2}}
$$

where $\overline{\text { rss }}$ is the mean values of each APs, now when distance with each RPs available the position of targets will be estimate using (6).

The estimated distance between RPs and targets can be estimated depending on spent time needs to reach receivers, where RPs could be access points or anchor points while the targets is the receives points. The exact distance can be calculating as in (7) [1].

$$
d_{i}=|| x-x_{i} \|=\sqrt{\left(\mathrm{x}-x_{i}\right)^{2}+\left(\mathrm{y}-y_{i}\right)^{2}} i=1.2 \ldots . k
$$

The distance between RPs and targets can be calculate depending on time of arrival as in (8) [1]:

$$
d_{i}=C *\left(\text { time }_{\text {arrival }}-\text { time }_{\text {sent }}\right)
$$

where $\mathrm{C}$, is speed of light. As mentioned, there are constrains due to multipath environments. Therefore, (1) can be written as in (9) [1]:

$$
d_{i}=\left\|x-x_{i}\right\|+\beta_{i}+m_{i}
$$

where $\beta_{\mathrm{i}}(\mathrm{m})$ equal to 0 in line-of-sight (LOS) and greater than 0 in NLoS, $\mathrm{m}_{\mathrm{i}}$ is noise value.

To estimate targets position, reference path loss calculates in one meter which recommended in [23], in addition there is called interested distance which can calculate as in (10) [1], [24]:

$$
P L(d)=P l o-b_{i}-10 \gamma \log 10 \frac{\left\|x-x_{i}\right\|}{d_{o}}
$$

where Plo reference path loss, bi is positive bias, $\gamma$ is path loss exponent, $\mathrm{z}$ is the log normal shadowing express as a zero-mean Gaussian random variable, i. e. $\mathrm{n}_{\mathrm{i}} \sim \mathrm{N}\left(0 . \sigma_{\mathrm{ni}}^{2}\right)$ and $\mathrm{m}_{\mathrm{i}} \sim \mathrm{N}\left(0 . \sigma_{\mathrm{mi}}^{2}\right)$ is level of noise $(\mathrm{m})$.

When measurements of TOA and RSS as a one vector, $p=\left[p_{i}\right]^{T}$ and $d=\left[d_{i}\right]^{T},\left(p \cdot d \in \mathbb{R}^{N}\right)$. Then joint likelihood function can write as following [25]:

$$
\begin{aligned}
& \Lambda\left(p \cdot d \mid x \cdot b_{i} \cdot \beta_{i}\right)=p\left(p \mid x \cdot b_{i}\right) p\left(d \mid x \cdot \beta_{i}\right)=\frac{1}{\sqrt{2 \pi \sigma_{n i}^{2} \sigma_{m i}^{2}}} \\
& \left\{\exp -\frac{\left(p i-p o+b i+10 \gamma \log _{10} \frac{|| x-x i||}{d 0}\right)^{2} \sigma_{m i+(d i|| x-x i||-\beta i)}^{2} \sigma_{n i}^{2}}{\sigma_{n i}^{2} \sigma_{m i}^{2}}\right\}
\end{aligned}
$$

Also, the hybrid ML for $\left(\mathrm{x} \cdot \mathrm{b}_{\mathrm{i}} \cdot \beta_{\mathrm{i}}\right)$. can be written as in (12) [26]:

$$
\{x . b i . \beta i\} \operatorname{rgmin} \sum_{i=1}^{N} x . b i . \beta i
$$

However, according to [25], the equation above does not close from exact results, also it's difficult to distinguish between LOS and NLoS. Accordingly, hybrid ML is not perfect solution for multipath impact. The authors in [25], suggested an integrated TOA and RSS to employ the advantage for both techniques which can be mitigate the corresponding drawback for each one. To estimate targets located, trilateration method could be applied as shown in Figure 1, which depending on distances between RPs and targets [24], [27]. Then, the coordinate of targets can be calculated as following [28]. 


$$
\begin{aligned}
& x=\frac{x_{2}^{2}+d_{1}^{2}-d_{2}^{2}}{2 \times x_{2}} \\
& y=\frac{x_{3}^{2}+y_{3}^{2}+d_{1}^{2}-d_{3}^{2} \times x \times x_{3}}{2 \times y_{3}}
\end{aligned}
$$

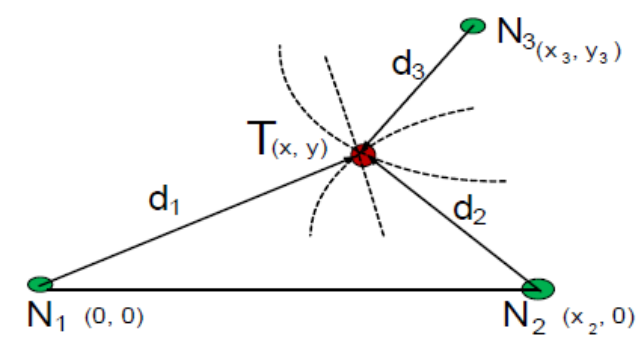

Figure 1. Estimate position using trilateration methods

\section{SYSTEM MODEL}

For simulation issues, wireless InSite package (WIP) used to implement case study building that corresponding with real one. Firstly, one of very important feature in WIP is the material's conductivity and permittivity calculated to be close from real building. According to [29], there are different effect based on the type of materials used for construction. Therefore, by simulate indoor environments, it should be taking into considerations the content of building. Table 1, depict the parameters of many materials which used to setup both $\sigma . \eta$ in WIP and calculate as following [30]:

$$
\begin{gathered}
\sigma=\mathrm{cf}^{\mathrm{d}} \mathrm{GHz} \\
\eta^{\prime}=\mathrm{af^{b }} \mathrm{GHz}
\end{gathered}
$$

where $a, b, c$ and d are defining by International Telecommunication Union (ITU) and worth to know that the ITU recommended to assign zero to constant $\mathrm{b}$ in term of permittivity to be constant for each frequency.

Table 1. Constant values for common indoor materials [30]

\begin{tabular}{ccccc}
\hline Material Type & \multicolumn{2}{c}{ Constants for calculating $\eta^{\prime}$} & \multicolumn{2}{c}{ Constants for calculating $\sigma$} \\
& $\mathrm{a}$ & $\mathrm{b}$ & $\mathrm{c}$ & $\mathrm{d}$ \\
\hline Concrete & 5.31 & 0 & 0.0326 & 0.8095 \\
Brick & 3.75 & 0 & 0.038 & 0 \\
Wood & 1.99 & 0 & 0.0047 & 1.0718 \\
Glass & 6.27 & 0 & 0.0043 & 1.1925 \\
Ceiling Board & 1.50 & 0 & 0.0005 & 1.1634 \\
Plaster Board & 2.94 & 0 & 0.0116 & 0.7076 \\
Floor Board & 3.66 & 0 & 0.0044 & 1.3515 \\
Metal & 1 & 0 & $10 \mathrm{E} 7$ & 0 \\
\hline
\end{tabular}

In this paper, the transmitters setup based on $2.4 \mathrm{GHz}$ frequency to deal with experimental transmitters. For calculate conductivity and permittivity, MATLAB geographic user interface (GUI) designed to implement conductivity and permittivity calculations. The input of GUI is the type of required material and the operating frequency. The output is the suitable conductivity and permittivity for selected materials. By apply (16) and (17), the conductivity and permittivity for $2.4 \mathrm{GHz}$ as show in Table 2 will be gotten to be ready to use in WIP. Moreover, in Table 1 clearly noted the permittivity equal to constant a due to constant $b$ equal to zero. The three dimensional (3D) designed with exactly real building measurements based on WIP as shown in Figure 2 after prepared the required parameters of materials. In the selected areas as shown in Figure 3, 80 points tested to be reference RSS in addition to 9 targets deployed in interested area. Such building is separated to 7 environments to assigned specific parameters when estimate the targets.

The reference pointes tested by using WIP in simlation side and Net Spot spftware in expermintal side, such software has a lot of abilities to measure the RSS that propoagted in interested area without connect to those sources. The other important things is the impact of other sources such as the movments of persons 
who use mobiles. Therefore, the measurements measured based on avaerege values of RSS at period of time and all steps of targets estimation depict in Figure 4.

Table 2. Conductivity and permittivity for $2.4 \mathrm{GHz}$

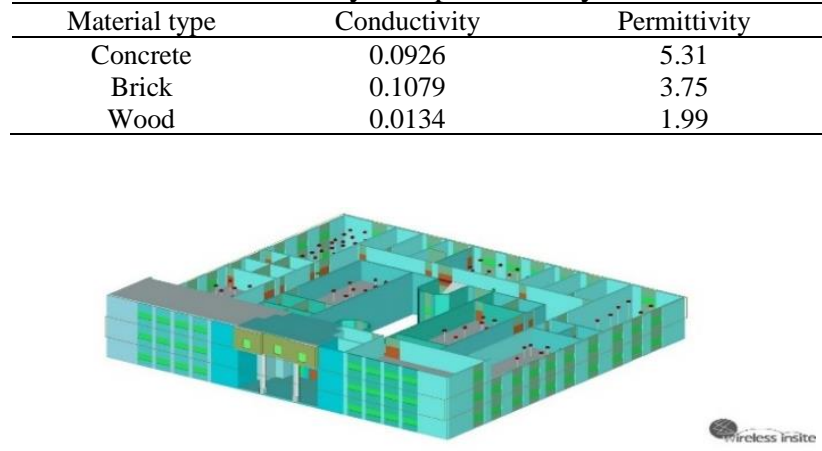

Figure 2. The case study building

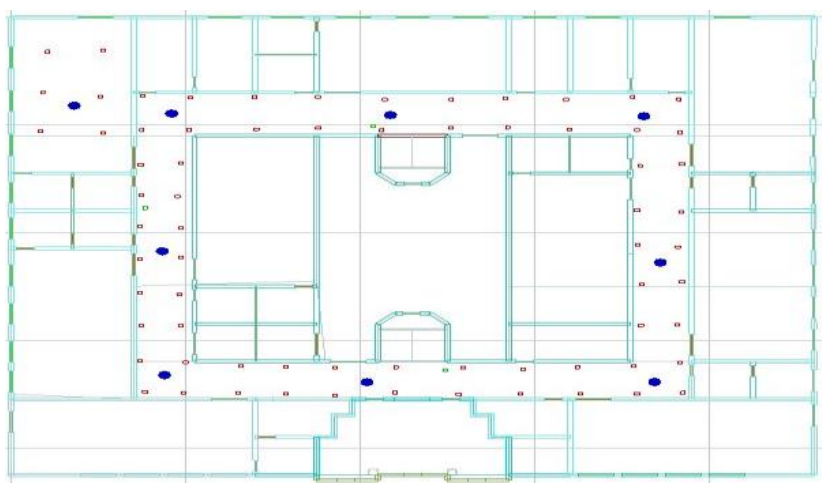

Figure 3. The targets and reference points deployements

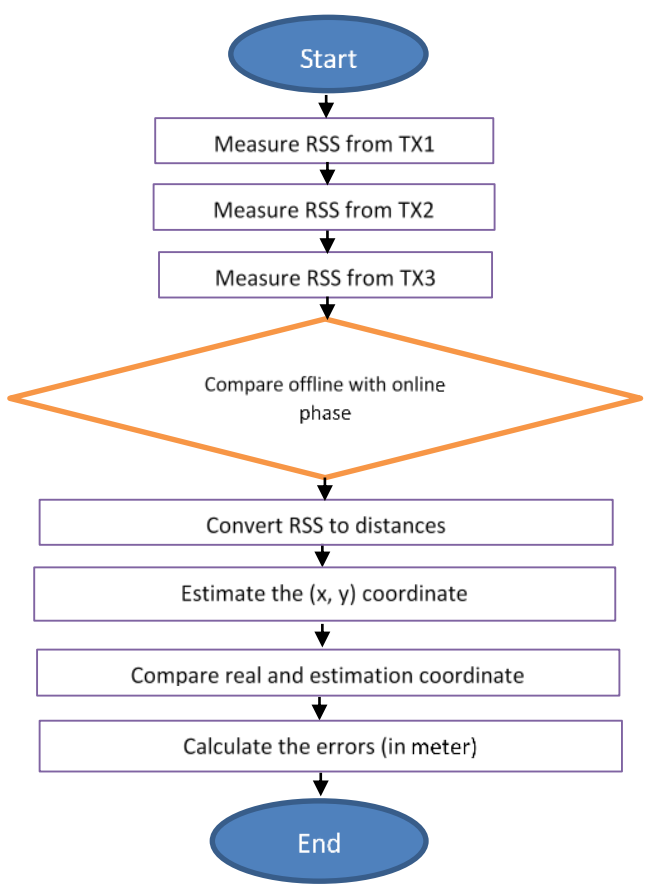

Figure 4. The flow chart of the proposed system 


\section{RESULTS AND DISCUSSION}

In case study building there are 9 targets was deployed, the RSS measurements play main role to find the accurate position of those targets. In Table 3, the measurements of test and reference RSS listed. In case of the RSS measurements are inaccurate comparing with the reference one as clearly shown in Table 3, the system will be inaccurate also.

The distances of targets will calculate based on (13) when the RSS measurements available to find the location in first estimation. In this scenario, the error is high but this step applied to determine the environments of the targets and this very useful for next step. Table 4, shows the estimate and the real coordinates to determine the environments. The error in first estimation was $(2.6 \mathrm{~m})$, but even with this error the environments determined to apply the second step by find nearest point and then final estimation. To modify the RSS measurements to be so close from reference one, nearest points applied by using (4) through (6) to find nearest access point (APs) and correct the measurements. In Table 5, clearly noted how to the RSS values modified to be nearest from Predictable one.

Table 3. The RSS measurements before matching data

\begin{tabular}{ccc}
\hline RXs & Test RSS $(\mathrm{dBm})$ & Reference RSS $(\mathrm{dBm})$ \\
\hline 1. & -52.66 & -46.57 \\
2. & -61.72 & -56.65 \\
3. & -52.13 & -54.22 \\
4. & -61.69 & -61.64 \\
5. & -54.44 & -49.21 \\
6. & -62.41 & -54.34 \\
7. & -65.88 & -53.67 \\
8. & -62.17 & -63.19 \\
9. & -63.34 & -54.18 \\
\hline
\end{tabular}

Table 4. The targets coordinates in real \& estimate scenarios.

\begin{tabular}{cccccc}
\hline $\mathrm{x}$-axis & y-axis & Estimat(x-axis) & Estimat(y-axis) & x-axis error(m) & y-axis error(m) \\
\hline 4.78 & -7.01 & 5.61 & -7.91 & 0.82 & 0.91 \\
10.07 & -7.65 & 9.08 & -7.59 & 0.98 & 0.05 \\
22.55 & -8.07 & 26.67 & -9.27 & 4.13 & 1.1 \\
37.26 & -7.86 & 35.65 & -10.76 & 1.62 & 0.91 \\
38.21 & -21.61 & 36.98 & -22.69 & 1.22 & 1.07 \\
37.78 & -32.83 & 40.55 & -33.85 & 2.17 & 1.01 \\
21.07 & -32.51 & 22.09 & -31.58 & 1.03 & 0.94 \\
9.45 & -32.09 & 9.49 & -33.12 & 0.05 & 1.02 \\
9.54 & -22.45 & 10.04 & -23.58 & 0.4 & 3.02 \\
\hline
\end{tabular}

Table 5. The RSS measurements after matching data

\begin{tabular}{ccc}
\hline RXs & Test RSS $(\mathrm{dBm})$ & Reference RSS $(\mathrm{dBm})$ \\
\hline 1. & -43.98 & -45.87 \\
2. & -54.34 & -55.65 \\
3. & -57.13 & -59.22 \\
4. & -61.69 & -60.64 \\
5. & -47.35 & -48.21 \\
6. & -54.89 & -56.34 \\
7. & -57.32 & -57.67 \\
8. & -62.88 & -63.19 \\
9. & -57.34 & -58.18 \\
10. & -51.21 & -51.58 \\
11. & -70.23 & -70.33 \\
12. & -53.11 & -53.82 \\
13. & -53.69 & -53.66 \\
14. & -64.9 & -63.34 \\
15. & -65.65 & -66.78 \\
16. & -64.9 & -64.22 \\
\hline
\end{tabular}

The second step apply to find accurate position, in this step dynamic parameter assigned based on different areas. In Figure 5, the calculation of errors recalculated based on the new measurements denoted by (OP-RSS) and parameters, the results shown error $(0.18 \mathrm{~m})$ in distance $(34 \mathrm{~m})$ between targets and transmitter. By using the measurements obtained from WIP, the location of targets estimated based on dynamic TOA denoted by ( D-TOA) and the error as shown in Figure 6, is (0.221) therefore, the RSS is slightly better than 
TOA. Finally, Table 6, shown coparsion betweem proposed technique in term of OP-RSS and D-TOA compared with traditional RSS and TOA.

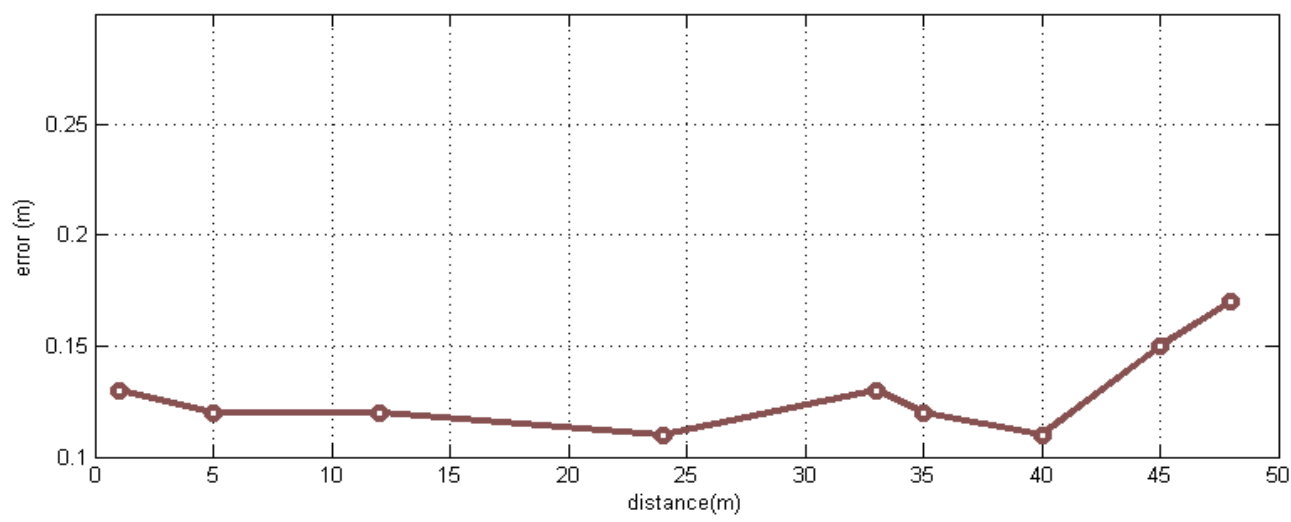

Figure 5. The errors (m) compared with the distance in second estimation based on OP-RSS

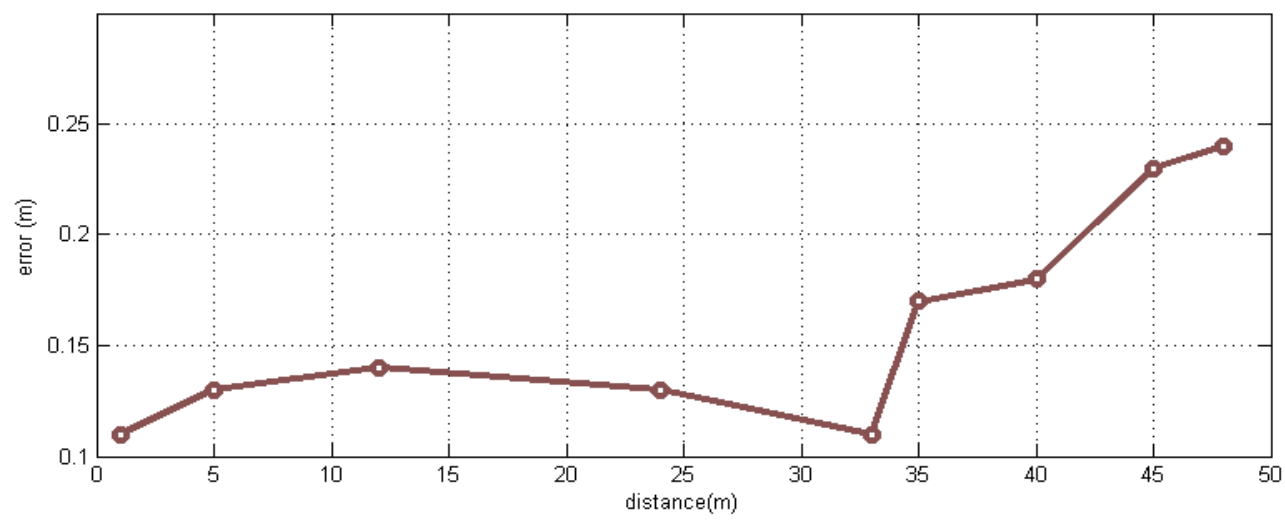

Figure 6. The errors (m) compared with the distance based on D-TOA

Table 6. The comparsion between propose technique and traditional RSS and TOA

\begin{tabular}{ccccc}
\hline lindex & Error $(\mathrm{m})$ based on TOA & Error $(\mathrm{m})$ based on D-TOA & Error $(\mathrm{m})$ based on RSS & Error(m) based on OP-RSS \\
\hline 1 & 1.22 & 0.11 & 1.01 & 0.13 \\
2 & 1.23 & 0134 & 1.13 & 0.121 \\
3 & 1.74 & 0,145 & 1.51 & 0.12 \\
4 & 1.66 & 0.139 & 1.27 & 0.115 \\
5 & 1.45 & 0.111 & 1.52 & 0.138 \\
6 & 2.28 & 0.171 & 2.23 & 0.122 \\
7 & 2.44 & 0182 & 2.14 & 0.113 \\
8 & 2.85 & 0.231 & 2.25 & 0.153 \\
9 & 2.56 & 0.242 & 2.28 & 0.173 \\
\hline
\end{tabular}

\section{CONCLUSION}

Indoor localization system carried out based on accurate RSS measurements, such system applied by using sequence of important procedures to reach in the end optimum system. First procedure is testing 78 RSS in term of simulation and experimental scenarios. The experimental side implemented based on Net Spot software while the simulation side was done by using WIP. Such measurements take in consideration the multiple source of noise such as the movements of humans into building who used the mobile phone in addition to number of deployed APs. The first estimation was very useful to determine the target's environment. The matching of the RSS values with nearest points in determined environment improved the accuracy. The second estimation is by assigning a specific parameter which calculated previously for each area into building. Those procedures improve the performance of the system. In the first estimation the average distance error was $(2.5 \mathrm{~m})$ while $(0.125 \mathrm{~m})$ in the second on. 


\section{REFERENCES}

[1] S. Tomic, M. Beko, R. Dinis, and P. Montezuma, "A robust bisection-based estimator for TOA-based target localization in NLOS environments," IEEE Communications Letters, vol. 21, no. 11, pp. 2488-2491, Nov. 2017, doi: 10.1109/LCOMM.2017.2737985.

[2] Z. Han, C. S. Leung, H. C. So, and A. G. Constantinides, "Augmented lagrange programming neural network for localization using time-difference-of-arrival measurements," IEEE Transactions on Neural Networks and Learning Systems, vol. 29, no. 8, pp. 38793884, Aug. 2018, doi: 10.1109/TNNLS.2017.2731325.

[3] H. A. Obeidat, O. A. Obeidat, M. F. Mosleh, A. A. Abdullah, and R. A. Abd-Alhameed, "Verifying received power predictions of wireless insite software in indoor environments at WLAN frequencies," Applied Computational Electromagnetics Society Journal, vol. 35, no. 10, pp. 1119-1126, Dec. 2020, doi: 10.47037/2020.ACES.J.351003.

[4] B. Jia, B. Huang, H. Gao, W. Li, and L. Hao, "Selecting critical WiFi APs for indoor localization based on a theoretical error analysis," IEEE Access, vol. 7, pp. 36312-36321, 2019, doi: 10.1109/ACCESS.2019.2905372.

[5] M. M. Abdulwahid, O. A. S. Al-Ani, M. F. Mosleh, and R. A. Abd-Alhameed, "Investigation of millimeter-wave indoor propagation at different frequencies," in 4th Scientific International Conference Najaf, SICN 2019, Apr. 2019, pp. 25-30, doi: 10.1109/SICN47020.2019.9019358

[6] E. Teoman and T. Ovatman, "Trilateration in indoor positioning with an uncertain reference point," in Proceedings of the 2019 IEEE 16th International Conference on Networking, Sensing and Control, ICNSC 2019, May 2019, pp. 397-402, doi: 10.1109/ICNSC.2019.8743240.

[7] M. M. Abdulwahid, O. A. S. S. Al-Ani, M. F. Mosleh, and R. A. Abd-Alhmeed, "Optimal access point location algorithm based real measurement for indoor communication," in Proceedings of the International Conference on Information and Communication Technology - ICICT '19, 2019, pp. 49-55, doi: 10.1145/3321289.3321300.

[8] S. Al-Jazzar, J. Caffery, and H. R. You, "Scattering-model-based methods for TOA location in NLOS environments," IEEE Transactions on Vehicular Technology, vol. 56, no. 2, pp. 583-593, Mar. 2007, doi: 10.1109/TVT.2007.891491.

[9] J. He, Q. Wang, Q. Zhang, B. Liu, and Y. Yu, "A practical indoor TOA ranging error model for localization algorithm," in IEEE International Symposium on Personal, Indoor and Mobile Radio Communications, PIMRC, Sep. 2011, pp. 1182-1186, doi: 10.1109/PIMRC.2011.6139685.

[10] W. Li, Y. Chen, and M. Asif, "A Wi-Fi-based indoor positioning algorithm with mitigating the influence of NLOS," in Proceedings of 2016 8th IEEE International Conference on Communication Software and Networks, ICCSN 2016, Jun. 2016, pp. 520-523, doi: 10.1109/ICCSN.2016.7587212.

[11] H. Ding, Z. Zheng, and Y. Zhang, "AP weighted multiple matching nearest neighbors approach for fingerprint-based indoor localization," in 4th International Conference on Ubiquitous Positioning, Indoor Navigation and Location-Based Services Proceedings of IEEE UPINLBS 2016, Nov. 2017, pp. 218-222, doi: 10.1109/UPINLBS.2016.7809974.

[12] S. Xia, Y. Liu, G. Yuan, M. Zhu, and Z. Wang, "Indoor fingerprint positioning based on Wi-Fi: An overview," ISPRS International Journal of Geo-Information, vol. 6, no. 5, p. 135, Apr. 2017, doi: 10.3390/ijgi6050135.

[13] H. X. Jian and W. Hao, "WIFI indoor location optimization method based on position fingerprint algorithm," in Proceedings - 2017 International Conference on Smart Grid and Electrical Automation, ICSGEA 2017, May 2017, vol. 2017-Janua, pp. 585-588, doi: 10.1109/ICSGEA.2017.123.

[14] S. Lee, J. Kim, and N. Moon, "Random forest and WiFi fingerprint-based indoor location recognition system using smart watch," Human-centric Computing and Information Sciences, vol. 9, no. 1, Feb. 2019, doi: 10.1186/s13673-019-0168-7.

[15] W. Gao, L. Pei, C. Xu, and P. Liu, "Crowdsensing-based organic fingerprint for Wi-Fi localization," in 4th International Conference on Ubiquitous Positioning, Indoor Navigation and Location-Based Services - Proceedings of IEEE UPINLBS 2016, Nov. 2017, pp. 79-88, doi: 10.1109/UPINLBS.2016.7809954.

[16] Y. H. Wu, Y. L. Chen, and S. T. Sheu, "Indoor location estimation using virtual fingerprint construction and zone-based remedy algorithm," Sep. 2016, doi: 10.1109/ICCPS.2016.7751132.

[17] X. Lou, Y. Jia, N. Jin, and M. Ye, "Indoor positioning based on hybrid algorithms: Wi-Fi fingerprint and ranging," in 2015 12th International Conference on Fuzzy Systems and Knowledge Discovery, FSKD 2015, Aug. 2016, pp. 2348-2352, doi: 10.1109/FSKD.2015.7382320.

[18] J. B. Xu, H. Q. Zhang, and J. L. Zhang, "Self-adapting multi-fingerprints joint indoor positioning algorithm in WLAN based on database of AP ID," in Proceedings of the 33rd Chinese Control Conference, CCC 2014, Jul. 2014, pp. 534-538, doi: 10.1109/ChiCC.2014.6896680.

[19] R. M. Zaal, F. M. Mustafa, E. I. Abbas, M. F. Mosleh, and M. M. Abdulwahid, "Real measurement of optimal access point localizations," IOP Conference Series: Materials Science and Engineering, vol. 881, no. 1, p. 12119, Aug. 2020, doi: 10.1088/1757899X/881/1/012119.

[20] H. Obeidat et al., "Indoor environment propagation review," Computer Science Review, vol. 37, p. 100272, Aug. 2020, doi: 10.1016/j.cosrev.2020.100272.

[21] O. A. Al-Ani, K. Muttair, and M. Mosleh, "Outdoor transmitter localization using multiscale algorithm," International journal of simulation: systems, science \& technology, Mar. 2019, doi: 10.5013/ijssst.a.20.s1.03.

[22] M. M. Abdulwahid, O. A. Shareef Al-Ani, M. F. Mosleh, and R. A. Abd-Alhmeed, "A comparison between different c-band and mmwave band frequencies for indoor communication," Journal of Communications, vol. 14, no. 10, pp. 892-899, 2019, doi: $10.12720 / \mathrm{jcm} .14 .10 .892-899$.

[23] Brian O'Keefe, "Finding location with time of arrival and time difference of arrival techniques," ECE Senior Capstone Project, 2017.

[24] M. Werner, "Prerequisites and foundations," in Indoor location-based services, Springer International Publishing, 2014, pp. $23-72$.

[25] S. Tomic and M. Beko, "Target localization via integrated and segregated ranging based on RSS and TOA measurements," Sensors (Switzerland), vol. 19, no. 2, p. 230, Jan. 2019, doi: 10.3390/s19020230.

[26] X. He, S. Badiei, D. Aloi, and J. Li, "WiFi iLocate: WiFi based indoor localization for smartphone," Apr. 2014, doi: 10.1109/WTS.2014.6835016.

[27] S. A. R. Zekavat and M. Buehrer, Handbook of Position Location: Theory, Practice, and Advances. John Wiley \& Sons, Inc., 2011.

[28] A. M. H. Khalel, "Position location techniques in wireless communication systems," Master Thesis, Blekinge Institute of Technology Karlskrona, Sweden, 2010.

[29] F. Agren, "Indoor radio propagation modelling with antenna placement optimization," Master Thesis, Lund University, Sweden, 2017.

[30] P. Series, "Effects of building materials and structures on radiowave propagation above about $100 \mathrm{MHz}$," Recommandation ITU-R, vol. 1 , pp. 2040-1, 2015 


\section{BIOGRAPHIES OF AUTHORS}

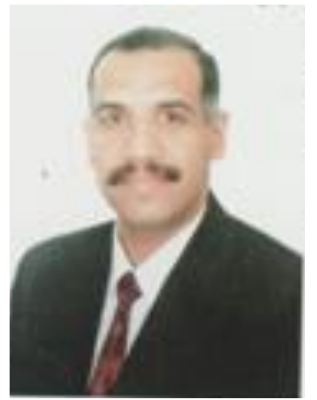

Omar Ibrahim Mustafa (D) SC SC He received his B.Sc, in 2001, from Middle Technical University, M.Sc degrees 2017, from Erciyes University, Turkey. He has been computer Eng. at the Middle Technical University, Iraq. He has more than 10 publications in National and International Journals. Also, participate in more than 5 International Conferences in the field of Communication Systems و University teacher and assistant department head at the Electrical Engineering Technical College for more than three years. He can be contacted at email: omdell_70@yahoo.com.

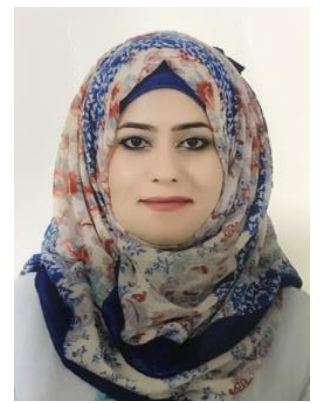

Hawraa Lateef joey (D) $8 \mathrm{SD}$ SC P received the B. Sc degree in 2011 and the M.Sc in 2020 both in the college of Engineering/Computer department from Baghdad University in Baghdad/Iraq, from 2012 till now she worked as a lecturer in the department of Computer Techniques Engineering at Al-Esraa University College. She can be contacted at email: hawraa@esraa.edu.iq.

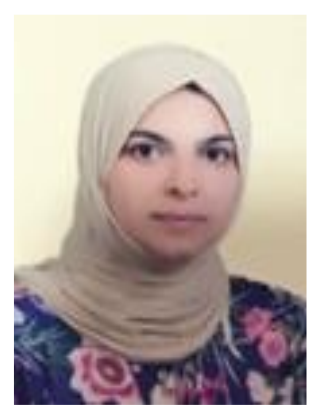

Noor Abd Al-Sultan (DD) SC SC P received the B.Sc in Computer and Information Engineering from AlMosul University, Iraq, in 2008, and M.Sc degrees in Electrical and Electronics Engineering from Gaziantep University, Turkey, in 2017. From 2009 and up to now, she worked as Demonstrator in the laboratory and Assistance Lecturer in the Computer Technology Engineering Department in AlHadbaa Unversity College/Mosul. She had attended several international conferences in Turkey and Iraq. In addition, she had achieved several international Certificates of CCNA and Web Design. She can be contacted at email: eng_nooralsultan24@yahoo.com.

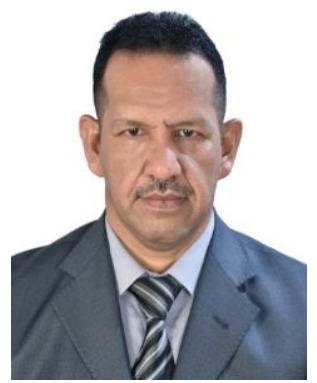

Ibrahim Zeghaiton Chaloob AL Mohammedi (iD) $8 \mathrm{SC}$ P was born in Al-Anbar - Fallujah - Iraq on 30 March 1972. He obtained his B. Sc. in Operation Research from, "AL Rafidain University College", in 2002, M. Sc. in Operation Research from College of Economy and Administration - Baghdad University (2006) .in Iraq and He obtained his PhD in Operation Research from Dept. of Decision Science, School of Quantitative Sciences, University Utara Malaysia (UUM) (2016). And he was Lecturer at College of Economy and Administration, Fallujah-Anbar University (2006). Lecturer at General Management Dept. College of Economy and Administration-Baghdad University (2007). On the same time work as manager in administration at the Department of performance evaluation, Director of Registration and Student Affairs Department at Ibn Sina University for Medical and Pharmaceutical Sciences 2017-2018. Representative of Ibn Sina University for Medical and Pharmaceutical Sciences for Sports Activities in the Ministry of Youth and Sports 2018. Member of the Ministry of Housing Planning Association 2017-2018 and now he is Lecturer in the Ministry of Higher Education and Scientific Research, Scientific supervision and evaluation apparatus 20192020. He can be contacted at email: chaloob@uofallujah.edu.iq. 